\title{
Influência do exercício físico agudo realizado até a exaustão sobre 0 número de leucócitos, linfócitos e citocinas circulantes
}

\author{
Jonato Prestes',2 - CREF 007176-G/PR \\ jonatop@gmail.com \\ Clílton Kraüss de Oliveira Ferreira² - CREF 043850-G/SP \\ clinicackof@uol.com.br \\ Anelena Bueno Frollini² \\ aninhafrollini@gmail.com \\ Rodrige Dias² \\ rdiasd@gmail.com \\ Felipe Fedrizzi Donatto2 - CRN 18/215/SP \\ ffdonatto@gmail.com
}

\author{
Marcia Grando Guereschi \\ mgueres@yahoo.com.br \\ Adrianne Christine Palanch2 \\ apalanch@unimep.br \\ Sérgio Eduardo de Andrade Perez' \\ seaperez@power.ufscar.br \\ Cláudia Regina Cavaglieri² - CRF $11 / 992 /$ SP \\ ccavagli@unimep.br

\begin{abstract}
1 Programa de Pós-graduação em Ciências Fisiológicas, Laboratório de Fisiologia do
2 Núcleo de Performance Humana, Mestrado em Educação Física, Faculdade de Ciências
\end{abstract} \\ Exercício, Universidade Federal de São Carlos/SP \\ da Saúde, Universidade Metodista de Piracicaba/SP
}

Prestes J, Ferreira CKO, Frollini AB, Dias R, Donatto FF, Guereschi MG et al. Influência do exercício físico agudo realizado até a exaustão sobre o número de leucócitos, linfócitos e citocinas circulantes. Fit Perf Journal 2007;6(1):32-7.

\begin{abstract}
Resumo - O objetivo deste estudo foi verificar os efeitos do exercício agudo sobre o número de leucócitos totais, linfócitos e citocinas circulantes. Foram utilizados ratos Wistar, com +2 meses, divididos em 3 grupos ( $n=6$, por grupo): 1) controle sedentário (C), 2) exercitado em intensidade leve até a exaustão (sem sobrecarga adicional) (EXL), e 3) exercitado em intensidade moderada até a exaustão (sobrecarga de $5 \%$ do peso corporal acoplado na região dorsal) (EXM). Foram analisados os leucócitos, linfócitos circulantes dos linfonodos mesentéricos e a concentração de citocinas. Aplicou-se o teste estatístico ANOVA two way, seguido de Post Hoc Tukey, com $\mathrm{p} \leq 0.05$. Foram observados aumento nos leucócitos e linfócitos circulantes para os grupos EXL e EXM comparados ao controle; redução nos linfócitos mesentéricos no EXL em relação ao controle; redução no TNF- $\alpha$ no grupo EXM; e aumento na IL-6 circulante no EXL quando comparados ao controle. Concluiu-se que, o exercício realizado até a exaustão pode promover leucocitose e linfocitose. $O$ exercício realizado por 10 horas em média (EXL) induz a redução nos linfócitos teciduais, podendo contribuir para a linfocitose nesta mesma situação. O exercício de 10 horas em média eleva a IL-6 e o exercício realizado até a exaustão com sobrecarga reduz o TNF- $\alpha$.
\end{abstract}

Palavras-chave: Exercício físico, sistema imune, linfócitos, citocinas.

Endereço para correspondência:

Rua Major José Inácio, 2400,13, Edifício Ouro Preto, Centro, São Carlos, SP, CEP 13.560-161.

Data de Recebimento: Junho / 2006

Data de Aprovação: Outubro / 2006

Copyright@ 2006 por Colégio Brasileiro de Atividade Física Saúde e Esporte. 
Influence of acute physical exercise on leukocytes, lymphocytes and circulating cytokines levels

The purpose of this issue was to verify the effects of exercise on leukocytes, lymphocytes count and seric cytokines levels. Wistar rats were used ( 2 months old), divided into three groups $(n=6)$ : 1) a sedentary control (C), 2) group exercised at low intensity until exhaustion (without additional load) (EXL), and 3) group exercised at moderate intensity until exhaustion (EXM) (additional load of $5 \%$ of their body weight adapted on their backs). The analyses performed were: total leukocytes and lymphocytes count, lymphocytes from lymph nodes and seric cytokines. The statistical analysis was done applying the ANOVA two way test, followed by Tukey's post hoc, with a $p \leq 0.05$. A significant increase in leukocytes and blood lymphocytes was observed for EXL and EXM in relation to control; it was also observed decrease in lymphocytes from lymph nodes in EXL as compared to control. For cytokines, it was observed decrease in TNF- $\alpha$. levels in EXM, and increase in IL-6 for EXL as compared to control. It was concluded that, exercise performed until exhaustion induces both, leukocytosis and lymphocytosis. Exercise performed during 10 hours in average (EXL) promotes reduction in tissue lymphocytes, contributing to lymphocytosis in this situation. Exercise of 10 hours in average increase IL- 6 and exercise to exercise exhaustion with additional load decrease TNF- $\alpha$.
Influencia del ejercicio físico agudo realizado hasta el agotamiento sobre el número de leucocitos, linfocitos y citocinas circulantes

El o etivo de este estudio fué verificar los efectos del ejercicio agudo sobre el número de leucocitos totales, linfocitos y citocinas circulantes. Fueron utilizados ratones Wistar, +2 meses, divididos en 3 grupos ( $n=6$, por grupo): 1) control sedentario (C), 2) ejercitado en intensidad leve hasta el agotamiento (sin sobrecarga adicional), (EXL) y 3) ejercitado en intensidad moderada hasta el agotamiento (sobrecarga de $5 \%$ del peso corporal acoplado en la región dorsal), (EXM). Fueron analizados los leucocitos, linfocitos circulantes y los linfonodos mesentéricos y concentración de citocinas. Se ha aplicado el test estadístico ANOVA two way, seguido de Post Hoc Tukey, con $p \leq 0.05$. Fué observado aumento en los leucocitos y linfocitos circulantes para los grupos EXL y EXM comparados al control; reducción en los linfocitos mesentéricos en el EXL relativo al control. Fué observado reducción en el TNF- $\alpha$ en el grupo EXM y aumento en la IL-6 circulante en el EXL cuando comparados al control. Se ha concluido que, el ejercicio realizado hasta el agotamiento puede promover leucocitosis y linfocitosis. El ejercicio realizado por 10 horas como promedio (EXL) induce a la reducción en los linfocitos tejiduales, pudiendo contribuir para la linfocitosis en esta misma situación. El ejercicio de 10 horas como promedio eleva hasta IL-6 y el ejercicio realizado hasta el agotamiento con sobrecarga reduce el TNF- $\alpha$.

Keywords: Ejercicio fisico, sitema inmune, linfocitos, citocinas

\section{INTRODUÇÃO}

A intensidade, a duração e a freqüência do exercício exercem papel chave na determinação das respostas imunológicas, podendo aumentar ou reduzir tal função 1,2. A prática de atividade física regular realizada em intensidade moderada pode levar à redução na ocorrência de infecções, especialmente do trato respiratório superior (ITRSs)'.

Por outro lado, treinamentos de alto volume e intensidade realizados por atletas têm sido relacionados com aumentos da susceptibilidade a ITRSs ${ }^{3}$. Treinamentos intensos podem, ainda, reduzir a função de linfócitos ou acelerar o processo de apoptose nestas células ${ }^{4}$.

O aumento no tráfico de linfócitos é tipicamente controlado pelas concentrações de catecolaminas, especialmente em atividades de curta duração ${ }^{5,6}$. As reduções observadas no número de linfócitos circulantes sofrem influências do cortisol, particularmente em exercícios de duração mais prolongada ${ }^{7,8}$.

O exercício físico afeta a produção sistêmica de citocinas, principalmente o Fator de Necrose Tumoral-alfa (TNF- $\alpha$ ), interleucina$1 \beta$, interferons, interleucina-6 (IL-6) e outras citocinas ${ }^{9,10,11}$.

A IL-6 é uma molécula de sinalização intercelular associada com o controle e a coordenação de respostas imunes, sendo secretada pelos macrófagos e linfócitos em resposta a lesão ou infecção ${ }^{12}$. As elevações na lL-6 em resposta ao exercício podem exercer um papel antiinflamatório, principalmente pela inibição na produção de TNF- $\alpha$, uma citocina tipicamente pró-inflamatória $^{13}$. O TNF- $\alpha$ induz efetivamente respostas inflamatórias locais e auxilia no controle de infecções ${ }^{14}$. A IL-2 exerce efeitos regulatórios sobre a maioria das células corporais, especialmente sobre as células imunes, e é produzida pelos linfócitos $T$ auxiliares e células "natural killers" (NK). Esta citocina exerce um importante papel nas respostas celulares humorais e inflamatórias ${ }^{15}$.

Oexercício extenuante demonstrou suprimir a função dos linfócitos T e NK, possivelmente comprometendo a produção de citocinas a partir destas células ${ }^{16}$. As ações da IL-2 incluem a estimulação da proliferação e diferenciação de células $B$ e T, a elevação da citotoxidade de linfócitos, ativação de monócitos/ macrófagos e a liberação de outras citocinas como TNF- $\alpha$ e IFN $\gamma^{17}$. São escassos os trabalhos que analisaram o efeito agudo do exercício realizado até a exaustão em diferentes intensidades sobre o número de linfócitos dos linfonodos mesentéricos, bem como se o exercício realizado até a exaustão pode modular a produção de citocinas, essenciais à resposta imune.

Considerando estas possíveis alterações imunes apresentadas, o objetivo deste trabalho está centrado em analisar o efeito agudo do exercício físico (natação) em diferentes intensidades sobre o número de leucócitos totais, linfócitos circulantes e teciduais e citocinas plasmáticas de ratos. 


\section{METODOLOGIA}

\section{Animais}

Ratos machos da linhagem Wistar (Rathus novergicus var, albinus, Rodentia, Mamalia), com 2 meses de idade, que foram obtidos do biotério Central da Universidade Metodista de Piracicaba.

Os animais receberam água e alimentação ad libitum e foram mantidos em ambiente com temperatura constante de $23^{\circ} \mathrm{C} \pm$ $2{ }^{\circ} \mathrm{C}$ e ciclo claro/escuro de $12 / 12$ horas, com luz acesa a partir das 6 horas, e em gaiolas coletivas ( 3 animais por gaiola). Antes de iniciar o período experimental, os animais permaneceram por 48 horas em adaptação às condições do biotério de pesquisa. presente estudo foi aprovado pela Comissão de Ética em Experimentação Animal da Universidade Federal de São Carlos (n0 protocolo: 017/2006).

\section{Grupos experimentais}

Os animais foram divididos em 3 grupos:

1) grupo controle - animal sedentário, não tendo nenhuma participação nos protocolos de exercício físico, identificado pela sigla $(\mathrm{C})$;

2) grupo com exercício físico agudo - animais realizaram uma única sessão de exercício físico até a exaustão na intensidade leve, identificado pela sigla (EXL);

3) grupo com exercício físico agudo - animais realizaram uma única sessão de exercício físico até a exaustão na intensidade moderada, identificado pela sigla (EXM).

Para todos os grupos experimentais $n=6$ animais.

\section{Exercício Físico}

A natação foi realizada em um tanque com a temperatura de $32^{\circ} \mathrm{C}$. Para realização do exercício na intensidade moderada, cargas adicionais com $5 \%$ do peso corporal dos animais foram acopladas em suas regiões dorsais, o que corresponde a uma intensidade abaixo do limiar anaeróbio ${ }^{18}$. No exercício de intensidade leve não foram utilizadas cargas adicionais. Os animais dos grupos experimentais foram submetidos separadamente ao exercício físico e sacrificados de 3 a 4 minutos após o final das sessões de exercício estipuladas, para análise das variáveis sanguíneas e teciduais, o que aconteceu no mesmo período do dia (entre 14 e 17 horas), incluindo o grupo controle.

Portanto, todos os animais foram submetidos à mesma influência do ritmo circadiano hormonal, minimizando possíveis alterações fisiológicas decorrentes de coletas realizadas em momentos diferentes do dia. $\bigcirc$ critério utilizado para determinar a exaustão, foi o momento em que os animais afundavam e não conseguiam mais chegar à superfície do tanque. Adicionalmente, o tempo total médio de natação para o grupo exaustão leve (EXL) foi de 10 horas e do grupo exaustão moderado (EXM) foi de 1 hora.

\section{Leucócitos Tołais}

O sangue foi colhido em tubo de vidro que continha EDTA (100 $\mu$ l para 3,5 $\mathrm{ml}$ de sangue); uma alíquota de $10 \mu \mathrm{L}$ do sangue foi retirada, colocada em um tubo de plástico, no qual foram acrescentados $190 \mu \mathrm{L}$ do corante TURKEY (Sigma, St. Louis, MO, USA). Com auxílio de pipeta o tubo foi homogeneizado, e a câmara de Neubaver foi preenchida, sendo realizada a contagem total dos leucócitos através do microscópio. Os resultados foram expressos x 106, seguindo as descrições de Dornfest et al. ${ }^{19}$.

\section{Conłagem de Linfócitos Circulantes}

O sangue foi colhido em tubo de vidro que continha EDTA, em seguida Foi realizado o esfregaço, a lâmina foi seca à temperatura ambiente (2 a 3 minutos), sendo feita a coloração (3ml MAY GRUNWALD e GIEMSA, corantes) (Sigma, St. Louis, MO, USA); após a secagem a leitura foi procedida no aparelho LEUCOTRON TP. Esta metodologia foi realizada acompanhando as especificações propostas por Dornfest et al. ${ }^{19}$.

\section{Obłenção dos linfócitos dos linfonodos mesen- téricos}

Após a retirada dos linfonodos mesentéricos, acrescentaramse $10 \mathrm{ml}$ de PBS; o líquido foi filtrado no tubo de ensaio 1 e centrifugado por 1 minuto a $2000 \mathrm{rpm}$. Em seguida, o Pelet foi ressuspendido no agitador em $10 \mathrm{ml}$ de PBS tubo 1. Uma parte de $100 \mu \mathrm{L}$ da amostra do tubo 1 foi colocada em outro tubo, ao qual acrescentaram-se $900 \mu \mathrm{L}$ de PBS, tubo 2; $100 \mu \mathrm{L}$ da amostra do tubo 2 foram retirados e colocados em um tubo de plástico. Posteriormente, acrescentaram-se $100 \mu \mathrm{L}$ de Triplan Blue (Sigma, St. Lovis, MO, USA), preenchendo a câmara de Neubaver; em seguida, procedeu-se à contagem do número total de linfócitos dos linfonodos mesentéricos no microscópio. Os resultados foram expressos x 106, seguindo a metodologia descrita por Serrano et al. ${ }^{20}$.

\section{Produção sérica de IL-2, IL-6 e TNF- $\alpha$}

As dosagens de IL-2, IL-6 e TNF- $\alpha$ foram realizadas a partir da coleta do soro do sangue dos animais e determinadas pelo método ELISA, seguindo as especificações correspondentes ao Kit (R\&D Systems, Minneapolis, MN), de acordo com as descrições de Cavaglieri et al. ${ }^{21}$.

\section{Tratamento Estatístico}

Todos os dados foram expressos como média \pm Erro Padrão da Média (EPM). A análise estatística foi realizada inicialmente pelo teste de normalidade Kolmorogorov-Smirnov e pelo teste de homocedasticidade (critério de Bartlett). Todas as variáveis apresentaram distribuição normal e homocedasticidade, sendo utilizado o teste Anova two way (levando-se em consideração as variáveis intervenientes, intensidade x duração); quando a diferença apresentada era significativa, aplicava-se o teste de Tukey para as comparações múltiplas. Em todos os cálculos foi fixado um nível crítico de $5 \%(p<0,05)$. O software utilizado em todos os testes estatísticos foi o Statistica ${ }^{\circledR}$ 6.1.

\section{RESULTADOS}

Os grupos exercitados apresentaram leucocitose quando comparados ao controle $(p<0,05)$, EXL aumentou $84,5 \%$ e EXM aumentou $90,53 \%$. Na comparação entre os grupos exercitados, não foram observadas diferenças estatisticamente significativas 
(Tabela 1). Nos linfócitos circulantes, foi observada linfocitose significativa nos grupos exercitados em relação ao controle ( $p \leq 0,05)$, ao passo que o grupo EXL aumentou $87,55 \%$ e o grupo EXM aumentou 94,34\%. Na comparação entre os grupos exercitados, não foram observadas diferenças estatisticamente significativas (Tabela 1). Nos linfócitos teciduais houve diminuição de $18,26 \%$ no grupo EXL em relação ao controle ( $p \leq 0,05)$. Na comparação entre os grupos exercitados, o grupo EXM apresentou maior número de linfócitos teciduais $(31,7 \%)$ quando comparado ao EXL (Tabela 1).

Em relação à concentração sérica de IL-2 não foram encontradas diferenças estatisticamente significativas em nenhum dos grupos exercitados quando comparados com o controle e nem entre os grupos exercitados (Tabela 2).

Foi observado aumento significativo de $36,6 \%$ na concentração circulante de IL-6 no grupo exaustão leve (EXL) em relação ao controle, sendo que, EXM não apresentou alteração em relação ao controle $(p<0,05)$.

Na comparação entre grupos, observou-se redução de 40,3\% na concentração de IL-6 no grupo EXM quando comparado ao grupo EXL (Tabela 2).

Foi detectada redução de 26,19\%, na concentração circulante de TNF- $\alpha$ no grupo EXM quando comparado ao controle. $\mathrm{Na}$ comparação entre os grupos exercitados, não foram observadas diferenças significativas, na concentração circulante de TNF- $\alpha$ (p $<0,05$ ) (Tabela 2).

\section{Discussão}

A leucocitose pode aumentar linearmente de acordo com a elevação da intensidade do exercício, sendo este aumento, em parte, mediado pela liberação de catecolaminas ${ }^{8,22,23}$. Estudo realizado por Hong et al. ${ }^{24}$ apontou que 20 minutos de exercício físico realizado em esteira ergométrica numa intensidade de 65-70\% do VO2max induziu leucocitose em associação com o aumento das concentrações de catecolaminas.

Esta leucocitose induzida pelo exercício físico também foi encontrada no atual trabalho, pelos aumentos significativos detectados no número de leucócitos totais nos grupos exercitados quando comparados ao grupo controle (Tabela 1). A leucocitose, que se mostrou percentualmente maior no grupo exaustão moderado em comparação com exaustão leve, pode ter sido causada pela intensidade mais elevada do exercício no grupo moderado ${ }^{8,23}$. $\bigcirc$ aumento no percentual de linfócitos circulantes (linfocitose) resultante de exercício é passageiro e, provavelmente, se deve à liberação dos hormônios do estresse, principalmente a adrenalina 25 , aumentando a liberação de células de seus compartimentos para a circulação sangüínea. Hong et al. ${ }^{24}$ observaram que um período de 20 minutos de esteira ergométrica promoveu aumento no percentual de linfócitos circulantes. Em homens fisicamente ativos que realizaram duas sessões de endurance de curta duração (20 minutos cada) no mesmo dia, foram observados aumentos nos linfócitos circulantes ${ }^{26}$. Recentemente, Nieman et al. ${ }^{27}$ analisaram o efeito da caminhada de 30 minutos na resposta imune em mulheres adaptadas a esta atividade, tendo verificado

Tabela 1

ContAgem total de Leucócitos, LiNFócitos CIRCULANTES E teCIDUAIS

\begin{tabular}{lcrr}
\hline $\mathrm{n}^{\circ}$ cél $x 106$ & C & EXL & EXM \\
\hline Leucócitos & $4,12 / 0,14$ & $7,60 / 0,33^{*}$ & $7,85 / 0,35 *$ \\
Linfócitos & $2,65 / 0,0008$ & $4,97 / 0,007^{*}$ & $5,15 / 0,0061^{*}$ \\
Linfócitos Teciduais & $157,00 / 5,28$ & $128,33 / 4,56 *$ & $169,33 / 5,43$
\end{tabular}

Valores = média / Erro padrão da média. $C=$ Grupo controle, EXL= Exercício até a exaustão em intensidade leve, EXM= Exercício até a exaustão em intensidade moderada, ( $n=6$ para todos os grupos experimentais). *Diferença significativa quando comparado ao grupo controle. \#Diferença significativa entre EXL e EXM $(p<0,05)$

TABela 2

Concentração SÉRICA dAS CITOCINAS IL-2, IL-6 E TNF- $\alpha$

\begin{tabular}{lccc}
\hline (pg/ml) & C & EXL & EXM \\
\hline IL-2 & $56,2 / 7,01$ & $52,31 / 3,36$ & $59,8 / 4,4$ \\
IL-6 & $267,88 / 9,86$ & $364,88 / 7,76^{*}$ & $259,98 / 23,18 \#$ \\
TNF- $\alpha$ & $5,46 / 0,2$ & $4,62 / 0,24$ & $4,03 / 0,03^{*}$ \\
\hline
\end{tabular}

Valores $=$ média $/$ Erro padrão da média. $C=$ Grupo controle, EXL= Exercício até a exaustão em intensidade leve, EXM= Exercício até a exaustão em intensidade moderada, ( $n=6$ para todos os grupos experimentais). *Diferença significativa quando comparado ao grupo controle. \#Diferença significativa entre EXL e $\operatorname{EXM}(p<0,05)$ 
que a caminhada numa intensidade de 60\%-65\% do VO2max foi associada com aumentos padrões, porém temporários, na contagem de células, sendo que os linfócitos circulantes contribuíram com $40 \%$ para a elevação total.

No presente estudo verificou-se aumento no percentual de linfócitos circulantes nos grupos exercitados quando comparados ao controle (Tabela 1). Igualmente aos leucócitos totais, a maior intensidade no grupo EXM promoveu aumento percentualmente superior no número de linfócitos circulantes em relação ao grupo exaustão leve.

Nielsen et al. ${ }^{28}$ demonstraram que, aproximadamente, 2/3 do total de linfócitos liberados para a circulação durante o exercício são provenientes do baço. Estando de acordo com Gabriel e Kindermann ${ }^{29}$, que propuseram os órgãos linfóides secundários como responsáveis pelo aumento de células circulantes.

Se o exercício for realizado por longos períodos ou em alta intensidade, a concentração total de linfócitos nos órgãos linfóides secundários pode diminuir ${ }^{8,30}$.

Neste sentido, estes resultados estão de acordo com a presente pesquisa, pois foram observadas reduções significativas na contagem de linfócitos dos linfonodos mesentéricos para o grupo exaustão leve, quando comparados ao controle sedentário (Tabela 1). Estes linfócitos, que possivelmente saíram do compartimento linfóide (linfonodo mesentérico), podem ter contribuído para linfocitose circulante observada neste mesmo grupo.

A intensidade promoveu maiores aumentos no número de células (neste caso dos linfócitos teciduais), já que observamos maior aumento no número de linfócitos teciduais no grupo EXM quando comparado ao grupo EXL (Tabela 1). Mcfarlin et al. ${ }^{26}$ demonstraram que não houve alteração estatisticamente significativa na IL-2 após uma sessão de uma hora na bicicleta ergométrica com $75 \%$ a $80 \%$ do VO2max. Nieman et al. ${ }^{31}$ demonstraram que as concentrações de IL-2 permaneceram próximas aos valores pré-prova ou em concentrações indetectáveis em indivíduos que competiram uma maratona.

Em camundongos jovens, submetidos ao treinamento de 8 semanas de corrida em esteira, não foram observadas alterações significativas na produção de IL-2 ${ }^{32}$. Pahlavani et al. ${ }^{33}$ demonstraram que não houve alterações na produção de IL-2 em ratos submetidos ao treinamento de natação, em relação aos animais sedentários.

Os resultados do atual estudo corroboram os estudos citados acima, pois, quando foram comparados os grupos exercitados com o grupo controle e os grupos entre eles, não foi observada alteração na concentração sérica de IL-2 (Tabela 2).

Toft et al. ${ }^{34}$ registraram que depois de 60 minutos de exercício em bicicleta ergométrica a IL-6 aumentou progressivamente. Oexercício concêntrico, como pedalar, resulta em aumentos menos pronunciados na IL-6 comparado com a corrida, que tem predominância de ações excêntricas ${ }^{17}$. Contudo, durante a corrida intensa, como a maratona, aumentos de 100 vezes na concentração de IL-6 foram demonstrados ${ }^{10,31}$. Durante o exercício, a IL-6 plasmática aumenta com a intensidade e duração da atividade ${ }^{10}$.

Hall et al. ${ }^{35}$ propuseram que a IL-6 é um potente modulador do metabolismo de lipídeos, através do aumento da oxidação de ácidos graxos e da reesterificação dos mesmos. Neste sentido, observou-se aumento significativo na IL-6 no grupo Exaustão Leve em comparação ao controle, e menor concentração no grupo EXM (duração do tempo de nado de 1 hora em média) em relação ao grupo EXL.

Vale destacar que, no grupo EXL, os animais nadaram em média 10 horas, sendo este exercício de características aeróbia e de longa duração e, conseqüentemente, priorizando o metabolismo lipídico e a produção desta citocina. A longa duração imposta no grupo EXL pode ter induzido maior microlesão muscular, contribuindo para maior produção local e sistêmica de IL-6, até mesmo porque os animais eram sedentários.

Em meninas que realizaram uma sessão de pólo aquático, com duração de 1 hora e 30 minutos, houve redução de 20\% no TNF- $\alpha^{11}$. No entanto, outro estudo não registrou nenhuma mudança no TNF- $\alpha$ circulante ${ }^{36}$. Rhind et al. ${ }^{37}$ demonstraram que a exposição prolongada ao frio (apesar da manutenção da temperatura corporal) provoca redução na expressão intracelular de TNF- $\alpha$ e leva a uma redução no TNF- $\alpha$ depois do exercício.

Petersen e Pedersen ${ }^{38}$ propuseram que o exercício induz a liberação de IL-6, seguido de aumentos na IL- 1 ra, IL- 10 (citocinas antiinflamatórias), proteína- $C$ reativa (CRP) e receptor solúvel de TNF- $\alpha$ (sTNF-R), inibindo a produção de TNF- $\alpha$.

Os resultados destes estudos citados foram similares aos resultados encontrados nesta pesquisa, pois foi observada redução no TNF- $\alpha$ circulante no grupo exercitado com sobrecarga até a exaustão.

\section{CONSIDERAÇÕES FINAIS}

Conclui-se, neste estudo, que, o exercício físico realizado até a exaustão promove leucocitose e linfocitose. $\bigcirc$ exercício de intensidade moderada pode induzir à leucocitose mais pronunciada.

Após o exercício prolongado (de 60 minutos a 10 horas de duração, em média), os linfócitos provenientes dos linfonodos mesentéricos foram reduzidos, migrando para a corrente sangüínea e contribuindo para a linfocitose induzida por esse tipo de atividade.

A concentração sérica de TNF- $\alpha$ foi reduzida apenas no exercício realizado com intensidade moderada. No entanto, para IL-6, o exercício mais prolongado ( 10 horas em média) e em intensidade leve induziu a aumentos expressivos desta citocina.

A imunologia do exercício necessita de futuras investigações com relação à redução funcional de células imunes, possível de ocorrer em indivíduos sedentários submetidos a exercício agudo.

Os efeitos positivos e negativos, crônicos e agudos do exercício, de diferentes intensidades, sobre o sistema imune precisam ser avaliados de forma mais acurada. 


\section{REFERÊNCIAS BIBLIOGRÁFICAS}

1. Matthews CE, Ockene IS, Freedson PS, Rosal MC, Merriam PA, Hebert JR. Moderate to vigorous physical activity and risk of upperrespiratory tract infection. Med Sci Sports Exerc 2002;34:1242-8.

2. Nieman DC. Exercise, upper respiratory tract infection, and the immune system. Med Sci Sports Exerc 1994;26:128-139.

3. Nieman DC, Pedersen BK. Exercise and immune function: recent developments. Sports Med 1999;27:73-80.

4. Quadrilatero J, Hoffman-Goetz L. N-Acetyl-L-Cysteine Inhibits Exercise-Induced Lymphocyte Apoptotic Protein Alterations. Med Sci Sports Exerc 2005;37(1):53-6.

5. Minetto M, Rainoldi A, Gazzoni M, Terzolo M, Borrione P, Termine A, et al. Differential responses of serum and salivary interleukin- 6 to acute strenous exercise. Eur J Appl Physiol 2005;93:679-86.

6. Landmann R. Beta-adrenergic receptors I human leucocyte subpopulations. Eur J Clin Invest 1992;22:30-6.

7. Jozsa R, Olah A, Cornélissen G, Csernus V, Otsuka K, Zeman $M$, et al. Circadian and extracircadian exploration during daytime hours of circulating corticosterone and other endocrine chronomes. Biomed Pharmacoth 2005;59:S109-16.

8. Pedersen BK, Hoffman-Goetz L. Exercise and the Immune System: Regulation, Integration and Adaptation. Physiol Rev 2000; 80:1055-81.

9. Jankord R, Jemiolo B. Influence of Physical Activity on Serum IL-6and IL-10 Levels in Healthy Older Men. Med Sci Sports Exerc 2004;36:960-4.

10. Ostrowski K, Schjerling P, Pedersen BK. Physical activity and plasma interleukin- 6 in humans - effect of intensity of exercise. Eur J Appl Physiol 2000;83:512-5.

11. Nemet D, Rose-Gottron CM, Mills PJ, Cooper DM. Effect of Water Polo Practice on Cytokines, Growth Mediators, and Leukocytes in Girls. Med Sci Sports Exerc 2003;35:356-63.

12. Pedersen BK, Toft AD. Effects of exercise on lymphocytes and cytokines. Br J Sports Med 2000;34:246-51.

13. Pedersen BK, Steensberg A, Fischer C, Keller C, Plomgaard P, Febbraio $M$, et al. Searching for the exercise factor: is IL-6 a candidate? J Muscle Res Cell Motil 2003;24:113-9.

14. Goebel MU, Mills PJ, Irwin MR, Ziegler MG. Interleukin-6 and Tumor Necrosis Factor- $\alpha$ Production After Acute Phychological Stress, Exercise, and Infused Isoproterenol: Differential Effects and Pathways. Psych Med 2000;62:591-8.

15. Janeway CA, Travers P. Immunobiology: The Immune System in Health and Disease. 2nd ed. London: Current Biology Ltd., 1996.

16. Starkie RL, Rolland J, Angus DJ, Anderson MJ, Febbraio MA. Circulating monocytes are not the source of elevations in plasma IL-6 and TNF-alpha levels after prolonged running. Am J Physiol 2001;280:C769-74.

17. Steensberg $A$, Toft $S P$, Schjerling $A D$, Halkjaer-Kristensen J, Pedersen BK. Plasma interleukin-6 during strenous exercise: role of adrenaline. Am J Physiol 2001;281:1001-4.

18. Voltarelli FA, Gobatto CA, Mello MAR. Determination of anaerobic threshold in rats using the lactate minimum test. Braz J Med Biol Res 2002;35:1389-94.

19. Dornfest BS, Lapin DM, Naughton BA, Adu S, Korn L, Gordon AS. Phenylhydrazine-induced leukocytosis in the rat. J Leuk Biol 1986;39:37-48.

20. Serrano MAR, Curi R, Parry-Billings M, Willians JF, Newsholme EA. Effects of glucocorticoids on lymphocytes metabolism. Am J Physiol 1993;264:E24-8.
21. Cavaglieri CR, Nishiyama A, Fernandes LC, Curi R, Miles EA, Calder PC. Differential effects of short-chain fatty acids on proliferation and production of pro- and anti-inflammatory cytokines by cultured lymphocytes. Life Sci 2003;73:1683-90.

22. Mills PJ, Rehman J, Ziegler MG, Carter SM, Dimsdale JE, Maisel AS. Nonselective beta blockade attenuates the recruitment of CD62L(-)T lymphocytes following exercise. Eur J Appl Physiol 1999; 79:531-4.

23. Bain BJ, Phillips D, Thomson K, Richardson D, Gabriel I. Investigation of the effect of marathon running on leucocyte counts of subjects of different ethnic origins: relevance to the etiology of ethnic neutropenia. British J Haematol 2000;108:483-7.

24. Hong S, Johnson TA, Farag NH, Guy HJ, Matthews SC, Ziegler MG, MILLS, P.J. Attenuation of T-limphocyte demargination and adhesion molecule expression in response to moderate exercise in physically fit individuals. J Appl Physiol 2005;98:1057-63.

25. Saxton JM, Claxton D, Winter E, Pockley AG. Peripheral blood leukocyte functional responses to acute eccentric exercise in humans are influenced by systemic stress, but not by exercise-induced muscle damage. Clinical Sci 2003;104:69-77.

26. Mcfarlin BK, Mitchell JB, Mcfarlin MA, Steinhoff GM. Repeated endurance exercise affects leukocyte number but not NK cell activity. Med Sci Sports Exerc 2003;35:130-8.

27. Nieman DC, Henson DA, Austin MD, Brown VA. Imune Response to a 30-Minute Walk. Med Sci Sports Exerc 2005;37:57-62.

28. Nielsen HB, Secher NH, Kristensen JH, Christensen NJ, Espersen K, Pedersen BK. Splenectomy impairs lymphocytosis during maximal exercise. Am J Physiol Regul Integr Comp Physiol 1997; 272:R1847-52.

29. Gabriel HH, Kindermann W. Adhesion molecules during immune response to exercise. Can J Physiol Pharmacol 1998;76:512-23.

30. Ronsen O, Pedersen BK, Oritsland BK, Bahr R, Kjedsen-Kragh J. Leukocyte counts and lymphocyte responsiveness associated with repeat bouts of strenuous endurance exercise. J Appl Physiol $2001 ; 91: 245-435$.

31. Nieman DC, Henson DA, Smith LL, Utter AC, Vinci DM, Davis JM, et al. Cytokine changes after a marathon race. J Appl Physiol 2001;91:109-14.

32. Kohut ML, Thompson JR, Lee W, Cunnick JE. Exercise training-induced adaptations of immune response are mediated by $\beta$-adrenergic receptors in aged but not young mice. J Appl Physiol 2004;96:1312-22.

33. Pahlavani MA, Cheung TH, Chesky JA, Richardson A. Influence of exercise on the immune function of rats of various ages. J Appl Physiol 1988;64:1997-2001.

34. Toft $A D$, Jensen LB, Bruunsgaard $H$, Ibfelt $T$, Halkejaer-Kristenses J, Febbraio $M$, et al. Cytokine response to eccentric exercise in young and elderly humans. Am J Physiol Cell Physiol 2002;283: C289-95.

35. Hall GV, Steensberg A, Massimo S, Fischer C, Keller C, Schierling $\mathrm{P}$, et al. Interleukin- 6 stimulates Lipolysis and Fat Oxidation in Humans. J Clin Endocrinol Metab 2003;88:305-10.

36. Timmons BW, Tarnopolsky MA, Bar-Or O. Sex-based effects on the distribution of NK cells subsets in response to exercise and carbohydrate intake in adolescents. J Appl Physiol 2006; 100:1513-9

37. Rhind SG, Castellani JW, Brenner IKM, Shephard RJ, Zamecnik $J$, Montain SJ, et al. Intracellular monocyte and serum cytokine expression is modulated by exhausting exercise and cold exposure. Am J Physiol Regul Integr Comp Physiol 2001;28:R66-75.

38. Petersen AMW, Pedersen BK. The anti-inflammatory effect of exercise. J Appl Physiol 2005;98:1154-62. 